\title{
GMR
}

\section{Meta-analysis of IL-6 -174G/C polymorphism and psoriasis risk}

\author{
G. Nie ${ }^{1.2}$, C.L. Xie ${ }^{1}$, Y.J. Cao ${ }^{1}$, M.M. Xu ${ }^{1}$, X. Shi ${ }^{1}$, A.L. Zou ${ }^{1}$ and J.H. Qi ${ }^{2}$ \\ ${ }^{1}$ Department of Dermatology, Huangshi Central Hospital, \\ Affiliated Hospital of Hubei Polytechnic University, Huangshi, China \\ ${ }^{2}$ Department of Hubei Key Laboratory of Kidney Disease Pathogenesis and \\ Intervention, Huangshi Central Hospital, \\ Affiliated Hospital of Hubei Polytechnic University, Huangshi, China \\ Corresponding author: J.H. Qi \\ E-mail: junhuaqi1989@163.com
}

Genet. Mol. Res. 15 (2): gmr.15028255

Received December 11, 2015

Accepted February 26, 2016

Published July 15, 2016

DOI http://dx.doi.org/10.4238/gmr.15028255

\begin{abstract}
Previous studies examining the association between interleukin-6 (IL-6) -174G/C polymorphism and psoriasis risk have produced inconsistent results. The aim of this study was to offer a comprehensive review of the association between IL-6 -174G/C polymorphism and psoriasis risk through a meta-analysis. Literature search of PubMed and Embase databases was conducted to identify all eligible studies published before October 29, 2015. Four case-control studies involving 651 psoriasis cases and 552 controls were included in this meta-analysis. Data were extracted, and pooled odds ratios (ORs) with $95 \%$ confidence intervals (CIs) were calculated to assess the associations. Combined analysis revealed a significant association between this polymorphism and psoriasis risk under the recessive model $(\mathrm{OR}=1.69,95 \% \mathrm{CI}=1.12-2.55, \mathrm{P}=0.013$ for $\mathrm{GG} v s \mathrm{GC}+\mathrm{CC})$, and the heterozygous comparison model $(\mathrm{OR}=1.70,95 \% \mathrm{CI}=1.29-2.23, \mathrm{P}<$ 0.001 for GG $v s \mathrm{GC})$. However, no significant association was observed under the allelic model $(\mathrm{OR}=1.37,95 \% \mathrm{CI}=0.99-1.89, \mathrm{P}=0.060$ for $\mathrm{G}$ $\left.v_{s} \mathrm{C}\right)$, the dominant model $(\mathrm{OR}=1.25,95 \% \mathrm{CI}=0.92-1.71, \mathrm{P}=0.152$
\end{abstract}


for $\mathrm{GG}+\mathrm{GC} v s \mathrm{CC})$, and the homozygote comparison model $(\mathrm{OR}=$ $1.62,95 \% \mathrm{CI}=0.79-3.32, \mathrm{P}=0.186$ for $\mathrm{GG} v \mathrm{CC})$. We conclude that the IL-6 -174G/C polymorphism contributes to psoriasis risk. However, further studies should be performed to validate our results.

Key words: Meta-analysis; Interleukin-6; Polymorphism; Psoriasis

\section{INTRODUCTION}

Psoriasis is a common chronic, relapsing, inflammatory skin disease that affects approximately $2 \%$ of the population worldwide (Ni and Chiu, 2014). The pathogenesis of psoriasis is far from clear. Previous studies suggest that inflammation mediated by T-lymphocytes plays a crucial role in the progression and prognosis of psoriasis (Bos and De Rie, 1999; Griffiths, 2003; Chamian and Krueger, 2004). IL-6 is a principal mediator of inflammation (Vural et al., 2010). Accumulating evidence suggests that IL-6 is implicated in the pathogenesis of psoriasis. For example, skin and serum IL-6 levels have been found to be elevated in psoriasis patients as compared with healthy controls (Neuner et al., 1991; Mizutani et al., 1997; Chamian and Krueger, 2004; Abanmi et al., 2005; Arican et al., 2005).

The human IL-6 gene, located on chromosome 7p21, spans $5 \mathrm{~kb}$, and contains four introns, five exons, as well as a proximal promoter region (Bowcock et al., 1988). Approximately 50 single nucleotide polymorphisms (SNPs) in the promoter region of the IL-6 gene have been identified (Terry et al., 2000; Pereira et al., 2011). Among these, the most studied SNP at position -174 (IL-6 -174G/C) can modify transcriptional regulation and cytokine levels, and has an impact on inflammatory phenotypes (Fishman et al., 1998). Previous studies have shown that IL-6 -174 G/C polymorphism is associated with the development and progression of various human diseases including systemic lupus erythematosus, neuroblastoma, coronary heart disease, HIV/AIDS, and nephritis (Sobti et al., 2010; Santos et al., 2011; Yin et al., 2012; Totaro et al., 2013; Yang et al., 2014).

Several case-control studies have been conducted to investigate the association between IL-6 -174G/C polymorphism and psoriasis risk (Baran et al., 2008; Settin et al., 2009; Boca et al., 2013; Białecka et al., 2015; Torres et al., 2015). However, the results were inconsistent. Some studies found significant associations between the IL-6 -174G/ $\mathrm{C}$ polymorphism and psoriasis, while others failed to discover such associations. These inconsistencies may be due to varying sample sizes as well as other factors. In this study, we performed a meta-analysis to increase the statistical power of all eligible case-control studies, and to obtain a precise estimate of the association between the IL-6 -174G/C polymorphism and psoriasis risk.

\section{MATERIAL AND METHODS}

\section{Literature search}

Literature search for potentially relevant studies were independently performed by two authors using the PubMed and Embase databases. The following search terms were used: ("IL6" or "interleukin-6") and ("psoriasis" or "psoriases" or "psoriatic") and ("polymorphism" or "SNP" or "single nucleotide polymorphism" or "variation" or "mutation"). Related reference 
articles were also manually screened to identify further eligible studies. The last search was updated on October 29, 2015.

\section{Study selection}

Studies included in this meta-analysis must meet the following inclusion criteria: a) case-control studies were conducted to evaluate the association between $I L-6-174 G / C$ polymorphism and psoriasis; b) $95 \%$ confidence intervals (CIs) for odds ratios (ORs) are available or can be calculated; c) genotype distributions in the control group satisfies the Hardy-Weinberg equilibrium (HWE). If several articles contained overlapping data sets, the most recent study or the one with the largest sample size was used. Reviews, summaries, abstracts, and case reports were excluded from our meta-analysis.

\section{Data extraction}

The following data were independently collected by two authors: first author, year of publication, population, sample size, genotype and allele frequencies in psoriasis cases and controls, and P value of HWE in control subjects. Differences in opinions were resolved by discussion between authors.

\section{Statistical analysis}

The Pearson $\chi^{2}$ test was used to determine whether the observed genotype frequencies in the controls were in HWE (Schaid and Jacobsen, 1999). Heterogeneity was determined using the Cochran Q-statistic and the $I^{2}$ test (Higgins and Thompson, 2002; Zintzaras and Ioannidis, 2005). ORs with corresponding $95 \% \mathrm{CIs}$ were calculated to assess the association between $I L-6-174 G / C$ polymorphism and psoriasis risk in five genetic models (G allele vs A allele, GG $v s \mathrm{GA}+\mathrm{AA}, \mathrm{GG}+\mathrm{GA} v s \mathrm{AA}, \mathrm{GG} v s \mathrm{AA}$, and GG $v s \mathrm{GA}$ ). If $\mathrm{P}<0.1$ for the Q-test or $I^{2}>50 \%$, which indicated between-study heterogeneity, the random-effect model was used. Otherwise, the fixed-effect model was applied. The significance of the pooled ORs was assessed using the Z-test. Begg's funnel plots and Egger tests were used to determine publication bias, in which $\mathrm{P}$ value $<0.10$ was considered statistically significant (Peters et al., 2006). All statistical tests were conducted using the STATA 12.0 software.

\section{RESULTS}

\section{Characteristics of included studies}

The procedures for including/excluding potential studies are presented in Figure 1. We retrieved 65 potentially relevant studies following initial search in the PubMed and EMBASE databases. In accordance with the inclusion criteria, four case-control studies with 651 psoriasis cases and 552 healthy controls were included in this meta-analysis. One study was excluded since the genotype distribution in the control group was inconsistent with the HWE (Settin et al., 2009). Two authors independently extracted information from all included studies, and a consensus was reached. The key information of the included studies is summarized in Table 1. 


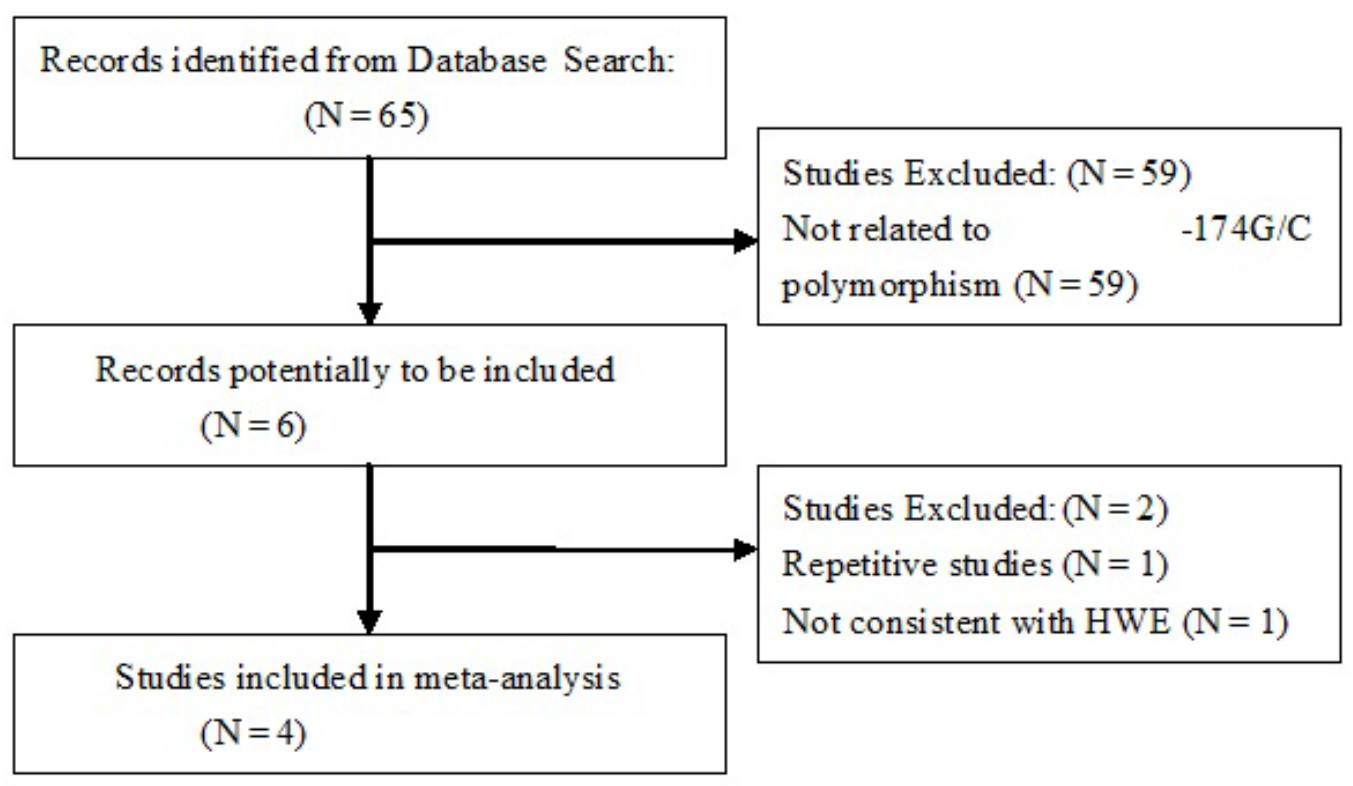

Figure 1. Flow diagram of study selection process.

Table 1. Key information of the four studies included.

\begin{tabular}{|c|c|c|c|c|c|c|c|c|c|c|c|c|c|}
\hline \multirow[t]{3}{*}{ Author } & \multirow[t]{3}{*}{ Year } & \multirow[t]{3}{*}{ Population } & \multicolumn{5}{|c|}{ Cases } & \multicolumn{6}{|c|}{ Controls } \\
\hline & & & \multicolumn{3}{|c|}{ Genotype } & \multicolumn{2}{|c|}{ Allele } & \multicolumn{3}{|c|}{ Genotype } & \multicolumn{3}{|c|}{ Allele } \\
\hline & & & GG & $\mathrm{GC}$ & $\mathrm{CC}$ & $\mathrm{G}$ & $\mathrm{C}$ & GG & $\mathrm{GC}$ & $\mathrm{CC}$ & $\mathrm{G}$ & $\mathrm{C}$ & $P_{\text {HWE }}$ \\
\hline Baran et al. & 2008 & Poland & 24 & 38 & 16 & 86 & 70 & 23 & 38 & 13 & 84 & 64 & 0.6915 \\
\hline Boca et al. & 2013 & Italy & 40 & 26 & 1 & 106 & 28 & 22 & 39 & 8 & 83 & 55 & 0.1371 \\
\hline Torres et al. & 2015 & Portugal & 42 & 45 & 13 & 129 & 71 & 72 & 110 & 24 & 254 & 158 & 0.0635 \\
\hline Bialecka et al. & 2015 & Poland & 137 & 182 & 87 & 456 & 356 & 42 & 106 & 55 & 190 & 216 & 0.4883 \\
\hline
\end{tabular}

$\mathrm{P}_{\mathrm{HWE}}, \mathrm{P}$ value for Hardy-Weinberg equilibrium (HWE).

\section{Meta-analysis results}

Significant between-study heterogeneity was observed in three genetic models $(\mathrm{G}$ allele $v_{s} \mathrm{C}$ allele, GG $v_{s} \mathrm{GC}+\mathrm{CC}$, and GG $v_{s} \mathrm{CC}$ ), as assessed with the Q-test and the $I^{2}$ test $\left(\mathrm{P}<0.1\right.$ or $\left.\mathrm{I}^{2}>50 \%\right)$. Therefore, the random-effect model was used to pool the results. No between-study heterogeneity was observed in the comparison of GG $+\mathrm{GC} v s \mathrm{CC}$ and GG vs $\mathrm{GC}$, and the fixed-effect model was used to pool these results. Meta-analysis results identified a significant association between this polymorphism and psoriasis risk under the recessive model $(\mathrm{OR}=1.69,95 \% \mathrm{CI}=1.12-2.55, \mathrm{P}=0.013$ for $\mathrm{GG} v s \mathrm{GC}+\mathrm{CC})$, the heterozygous comparison model $(\mathrm{OR}=1.70,95 \% \mathrm{CI}=1.29-2.23, \mathrm{P}<0.001$ for $\mathrm{GG} v s \mathrm{GC})$. However, no significant association was observed under the allelic model $(\mathrm{OR}=1.37,95 \% \mathrm{CI}=0.99-1.89$, $\mathrm{P}=0.060$ for $\mathrm{G} v s \mathrm{C})$, dominant model $(\mathrm{OR}=1.25,95 \% \mathrm{CI}=0.92-1.71, \mathrm{P}=0.152$ for $\mathrm{GG}+$ $\mathrm{GC} v \mathrm{CC})$, and the homozygote comparison model $(\mathrm{OR}=1.62,95 \% \mathrm{CI}=0.79-3.32, \mathrm{P}=0.186$ for GG $v_{s}$ CC) (Figures 2-6). Results are summarized in Table 2. 
Study

ID
$\%$

OR $(95 \% \mathrm{Cl}) \quad$ Weight

\begin{tabular}{|c|c|c|}
\hline Baran (2008) & $0.94(0.60,1.47)$ & 22.19 \\
\hline Boca (2013) & $\rightarrow 2.51(1.46,4.30)$ & 18.86 \\
\hline Torres (2015) & $1.13(0.80,1.61)$ & 26.79 \\
\hline Bialecka (2015) & $1.46(1.15,1.85)$ & 32.16 \\
\hline Overall $(1-$ squared $=66.5 \%, P=0.030)$ & $1.37(0.99,1.89)$ & 100.00 \\
\hline NOTE: Weights are from random-effect analysis & & \\
\hline 0.233 & 4.3 & \\
\hline
\end{tabular}

Figure 2. Forest plot using the random-effect model for determining the association between psoriasis risk and the IL-6 -174G/C polymorphism in the allelic model ( $\mathrm{G}$ allele $v_{s} \mathrm{C}$ allele).

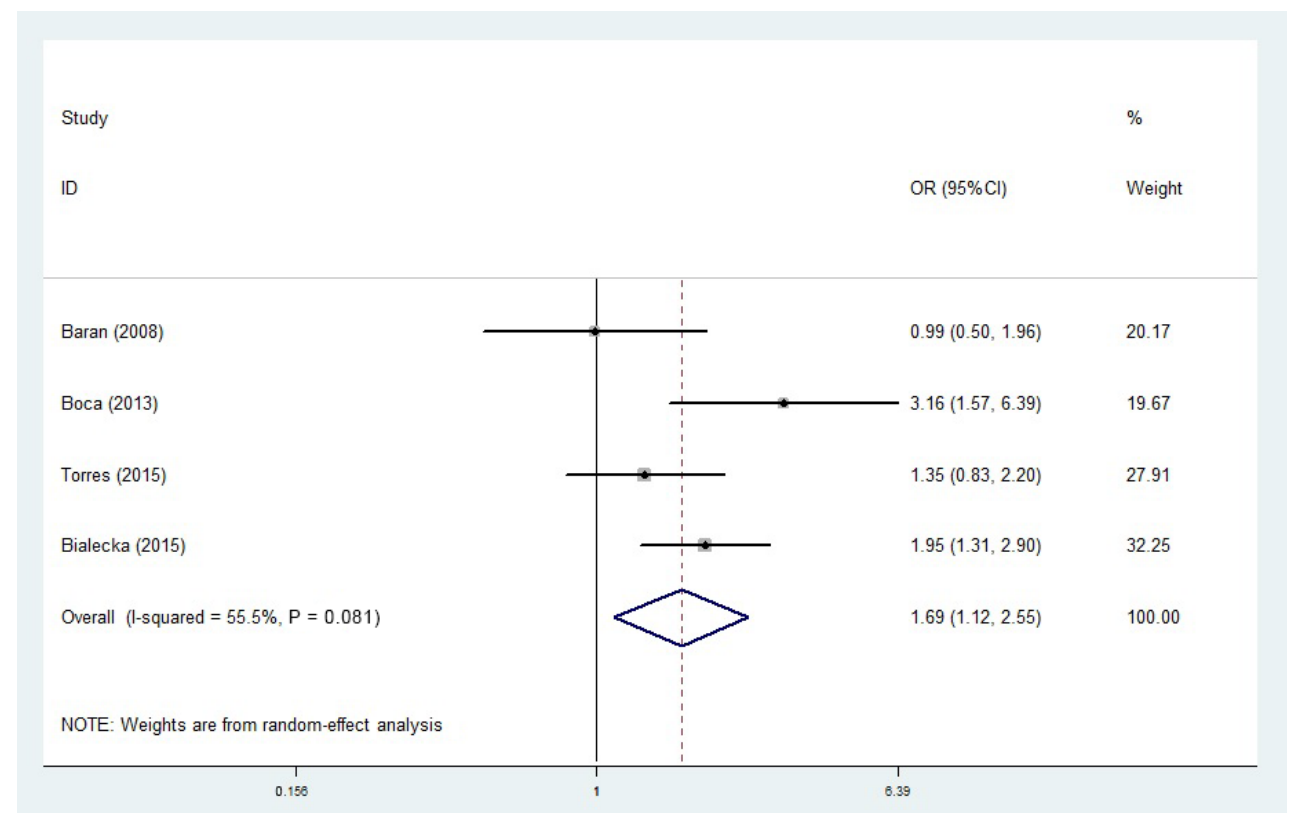

Figure 3. Forest plot using the random-effect model to determine the association between psoriasis risk and the IL-6 -174G/C polymorphism in the recessive model (GG vs GC + CC). 


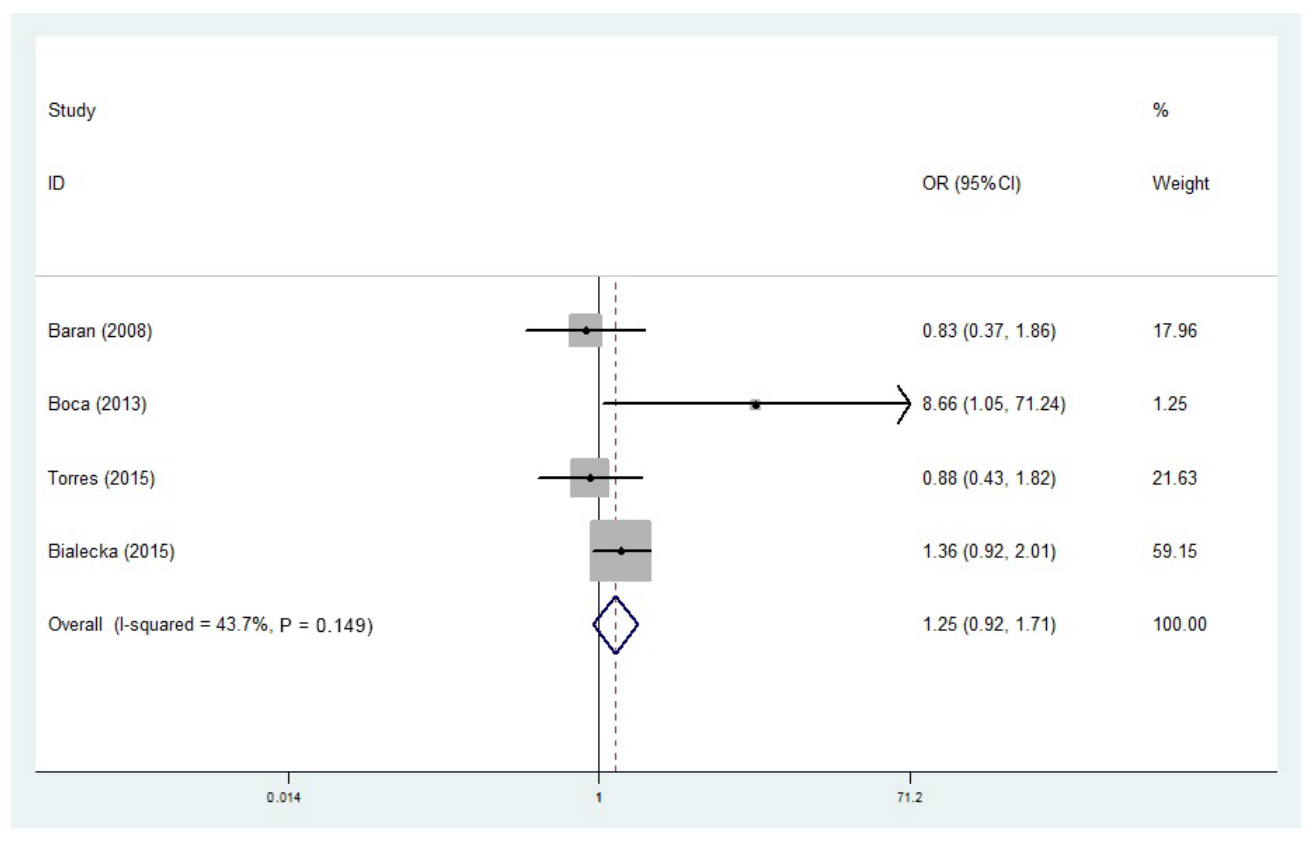

Figure 4. Forest plot using the fixed-effect model to determine the association between psoriasis risk and the IL-6 $-174 \mathrm{G} / \mathrm{C}$ polymorphism in the dominant model $(\mathrm{GG}+\mathrm{GC}$ vs $\mathrm{CC})$.

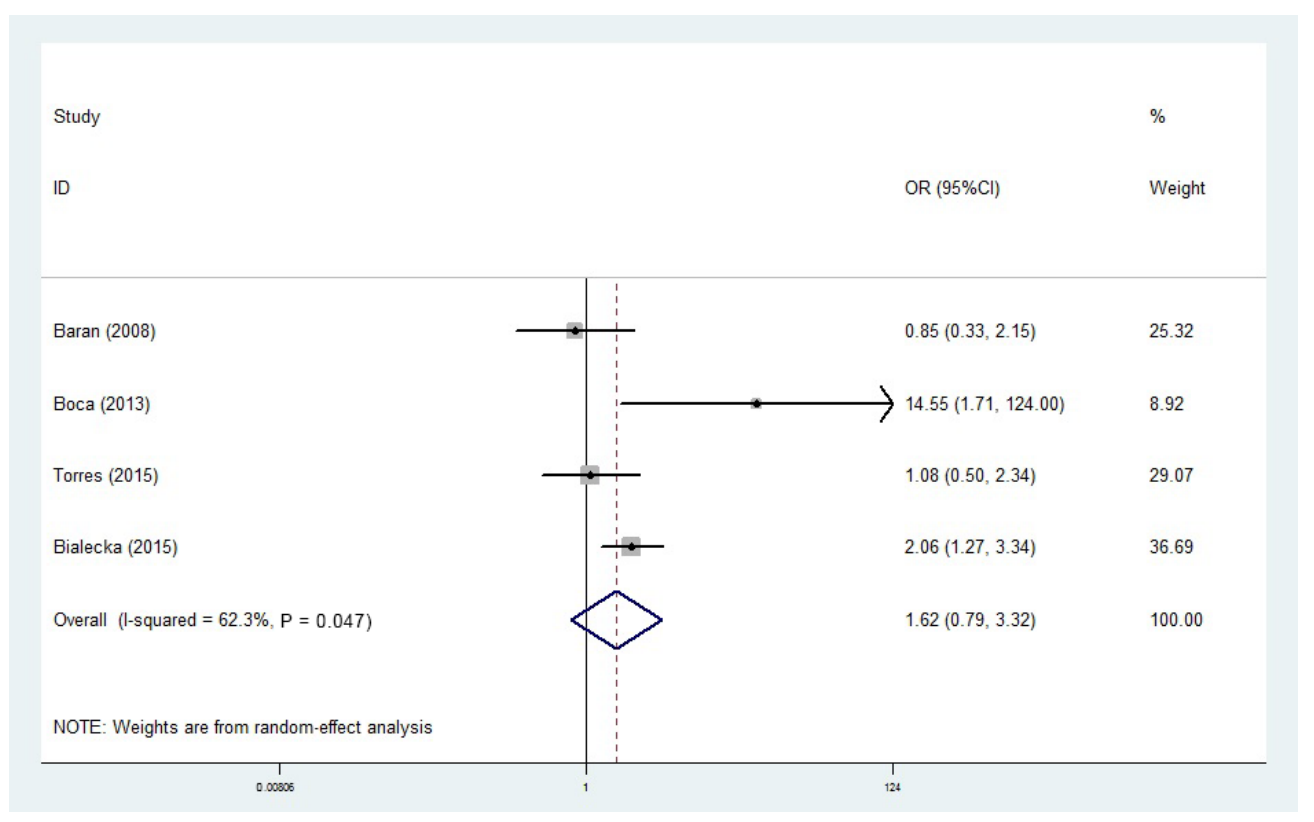

Figure 5. Forest plot using a random-effect model to determine the association between psoriasis risk and the IL-6 $-174 \mathrm{G} / \mathrm{C}$ polymorphism in the homozygote comparison model (GG vs CC). 


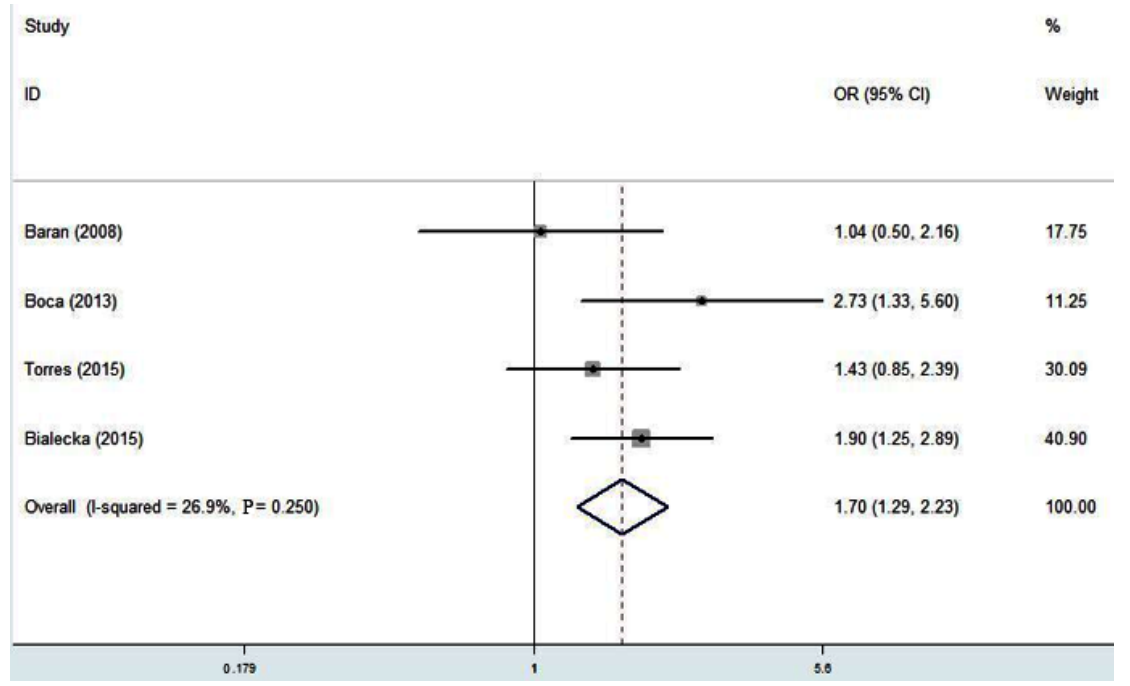

Figure 6. Forest plot using a fixed-effect model to determine the association between psoriasis risk and the IL-6 $-174 \mathrm{G} / \mathrm{C}$ polymorphism in the heterozygous comparison model ( $\mathrm{GG} v s \mathrm{GC})$.

Table 2. Meta-analysis of IL-6 -174G/C polymorphism and psoriasis risk.

\begin{tabular}{l|c|c|c|c|c|l}
\hline & \multicolumn{3}{|c|}{} & \multicolumn{3}{|c}{ Test of heterogeneity } \\
\hline Polymorphism & OR $(95 \% \mathrm{CI})$ & $\mathrm{Z}$ & $\mathrm{P}$ & $\mathrm{I}^{2}$ & $\mathrm{P}$ & Statistical model \\
\hline G allele $v s$ C allele & $1.37(0.99-1.89)$ & 1.88 & 0.060 & $66.5 \%$ & 0.030 & Random \\
\hline GG $v s$ GC + CC & $1.69(1.12-2.55)$ & 2.48 & 0.013 & $55.5 \%$ & 0.081 & Random \\
\hline GG + GC $v s$ CC & $1.25(0.92-1.71)$ & 1.43 & 0.152 & $43.7 \%$ & 0.149 & Fixed \\
\hline GG $v s$ CC & $1.62(0.79-3.32)$ & 1.32 & 0.186 & $62.3 \%$ & 0.047 & Random \\
\hline GG $v s$ GC & $1.70(1.29-2.23)$ & 3.80 & $<0.001$ & $26.9 \%$ & 0.250 & Fixed \\
\hline
\end{tabular}

\section{Publication bias}

As shown in Table 3, all P values of Begg's funnel plots and Egger tests were $>0.10$, indicating that there was no significant publication bias in all genetic models.

\section{Table 3. Results of Begg and Egger tests.}

\begin{tabular}{l|c|c}
\hline Model & Begg test $(\mathrm{P})$ & Egger test (P) \\
\hline G allele $v s$ C allele & 1.000 & 0.919 \\
\hline GG $v s$ GC + CC & 1.000 & 0.934 \\
\hline GG + GC $v s$ CC & 1.000 & 0.719 \\
\hline GG $v s$ CC & 1.000 & 0.798 \\
\hline GG $v s$ GC & 0.734 & 0.857 \\
\hline
\end{tabular}

\section{DISCUSSION}

The pathogenesis of psoriasis is a complex process in which both genetic and environmental factors play a role. Similarly, immunological disorders with inflammatory reactions mediated through T-lymphocytes are also relevant to psoriasis development (Bos and De Rie, 1999; Griffiths, 2003; Chamian and Krueger, 2004). IL-6 is one of the most potent pro-inflammatory cytokines, and is associated with numerous inflammatory diseases 
including psoriasis. In addition, elevated serum IL-6 level has been found in patients with psoriasis (Arican et al., 2005). Recently, several studies have tried to identify whether IL-6 -174G/C polymorphism is associated with psoriasis risk. However, the results of these studies are controversial. Meta-analysis has been recognized as a powerful statistical method that combines findings from independent studies to evaluate the effect of selected genetic polymorphism on the risk of a particular disease (Attia et al., 2003). To the best of our knowledge, no meta-analysis has been conducted to determine the association between IL-6 -174G/C polymorphism and psoriasis risk. Therefore, there is a need to conduct a metaanalysis using published data to clarify the inconsistent findings in this field of study.

In this meta-analysis, all the studies included have checked individual genotypes for quality control. The genotype distribution in the control group of each included study was consistent with HWE. Based on four case-control studies involving 651 psoriasis cases and 552 healthy controls, our study revealed a significant association between this gene polymorphism and psoriasis risk under the recessive model $(\mathrm{OR}=1.69,95 \% \mathrm{CI}=1.12-2.55, \mathrm{P}=0.013$ for $\mathrm{GG} v s \mathrm{GC}+\mathrm{CC})$, and the heterozygous comparison model $(\mathrm{OR}=1.70,95 \% \mathrm{CI}=1.29-2.23$, $\mathrm{P}<0.001$ for GG $v s \mathrm{GC})$. However, no significant association was observed under the allelic model $(\mathrm{OR}=1.37,95 \% \mathrm{CI}=0.99-1.89, \mathrm{P}=0.060$ for $\mathrm{G} v \mathrm{C})$, the dominant model $(\mathrm{OR}=$ $1.25,95 \% \mathrm{CI}=0.92-1.71, \mathrm{P}=0.152$ for $\mathrm{GG}+\mathrm{GC}$ vs $\mathrm{CC}$ ), and the homozygote comparison model $(\mathrm{OR}=1.62,95 \% \mathrm{CI}=0.79-3.32, \mathrm{P}=0.186$ for $\mathrm{GG} v s \mathrm{CC})$. Results showed obvious heterogeneity between studies in three genetic models (G allele vs C allele, GG vs GC + CC and GG vs CC), suggesting that the environment and ethnicity may contribute to differences in genetic backgrounds. Some limitations of our meta-analysis should be acknowledged. First, due to incomplete raw data or publication, several relevant studies were not included in our analysis. Second, psoriasis may also be modulated by several other genetic markers such as VEGF (Lee and Song, 2015) and TNF- $\alpha$ (Zhuang et al., 2013). Therefore, our meta-analysis showed that evaluation of potential gene-gene interactions is required to further elucidate the pathogenesis of psoriasis. Finally, due to the lack of raw data, we did not include factors such as gender, age, and clinical classification of the disease in our analysis, which may induce confounding bias. However, this meta-analysis also offered some clear advantages. First, as compared with individual studies, the sample size of our study was larger, which yielded results that were more reliable. Second, the associations between IL-6 -174G/C polymorphisms and psoriasis were evaluated under different genetic models.

In summary, this meta-analysis suggests that the IL- $6-174 \mathrm{G} / \mathrm{C}$ polymorphism may be associated with psoriasis risk. As few studies are available in this field, and current evidence remains limited, large-scale and well-designed studies must be performed to further support and validate our results.

\section{Conflicts of interest}

The authors declare no conflict of interest.

\section{REFERENCES}

Abanmi A, Al Harthi F, Al Agla R, Khan HA, et al. (2005). Serum levels of proinflammatory cytokines in psoriasis patients from Saudi Arabia. Int. J. Dermatol. 44: 82-83. http://dx.doi.org/10.1111/j.1365-4632.2004.02082.x

Arican O, Aral M, Sasmaz S and Ciragil P (2005). Serum levels of TNF-alpha, IFN-gamma, IL-6, IL-8, IL-12, IL-17, and IL-18 in patients with active psoriasis and correlation with disease severity. Mediators Inflamm. 2005: 273-279. 
http://dx.doi.org/10.1155/MI.2005.273

Attia J, Thakkinstian A and D'Este C (2003). Meta-analyses of molecular association studies: methodologic lessons for genetic epidemiology. J. Clin. Epidemiol. 56: 297-303. http://dx.doi.org/10.1016/S0895-4356(03)00011-8

Baran W, Szepietowski JC, Mazur G and Baran E (2008). IL-6 and IL-10 promoter gene polymorphisms in psoriasis vulgaris. Acta Derm. Venereol. 88: 113-116. http://dx.doi.org/10.2340/00015555-0427

Białecka M, Ostasz R, Kurzawski M, Klimowicz A, et al. (2015). IL6 -174G >C polymorphism is associated with an increased risk of psoriasis but not response to treatment. Exp. Dermatol. 24: 146-147. http://dx.doi.org/10.1111/ exd. 12577

Boca AN, Talamonti M, Galluzzo M, Botti E, et al. (2013). Genetic variations in IL6 and IL12B decreasing the risk for psoriasis. Immunol. Lett. 156: 127-131. http://dx.doi.org/10.1016/j.imlet.2013.09.028

Bos JD and De Rie MA (1999). The pathogenesis of psoriasis: immunological facts and speculations. Immunol. Today 20 : 40-46. http://dx.doi.org/10.1016/S0167-5699(98)01381-4

Bowcock AM, Kidd JR, Lathrop GM, Daneshvar L, et al. (1988). The human "interferon-beta 2/hepatocyte stimulating factor/interleukin-6" gene: DNA polymorphism studies and localization to chromosome 7p21. Genomics 3: 8-16. http://dx.doi.org/10.1016/0888-7543(88)90152-8

Chamian F and Krueger JG (2004). Psoriasis vulgaris: an interplay of $\mathrm{T}$ lymphocytes, dendritic cells, and inflammatory cytokines in pathogenesis. Curr. Opin. Rheumatol. 16: 331-337. http://dx.doi.org/10.1097/01. bor.0000129715.35024.50

Fishman D, Faulds G, Jeffery R, Mohamed-Ali V, et al. (1998). The effect of novel polymorphisms in the interleukin-6 (IL-6) gene on IL-6 transcription and plasma IL-6 levels, and an association with systemic-onset juvenile chronic arthritis. J. Clin. Invest. 102: 1369-1376. http://dx.doi.org/10.1172/JCI2629

Griffiths CE (2003). The immunological basis of psoriasis. J. Eur. Acad. Dermatol. Venereol. 17 (Suppl 2): 1-5. http:// dx.doi.org/10.1046/j.1468-3083.17.s2.1.x

Higgins JP and Thompson SG (2002). Quantifying heterogeneity in a meta-analysis. Stat. Med. 21: 1539-1558. http:// dx.doi.org/10.1002/sim. 1186

Lee YH and Song GG (2015). Vascular endothelial growth factor gene polymorphisms and psoriasis susceptibility: a meta-analysis. Genet. Mol. Res. 14: 14396-14405. http://dx.doi.org/10.4238/2015.November.18.3

Mizutani H, Ohmoto Y, Mizutani T, Murata M, et al. (1997). Role of increased production of monocytes TNF-alpha, IL1 beta and IL-6 in psoriasis: relation to focal infection, disease activity and responses to treatments. J. Dermatol. Sci. 14: 145-153. http://dx.doi.org/10.1016/S0923-1811(96)00562-2

Neuner P, Urbanski A, Trautinger F, Möller A, et al. (1991). Increased IL-6 production by monocytes and keratinocytes in patients with psoriasis. J. Invest. Dermatol. 97: 27-33. http://dx.doi.org/10.1111/1523-1747.ep12477880

Ni C and Chiu MW (2014). Psoriasis and comorbidities: links and risks. Clin. Cosmet. Investig. Dermatol. 7: 119-132.

Pereira DS, Garcia DM, Narciso FM, Santos ML, et al. (2011). Effects of 174 G/C polymorphism in the promoter region of the interleukin-6 gene on plasma IL-6 levels and muscle strength in elderly women. Braz. J. Med. Biol. Res. 44: 123-129. http://dx.doi.org/10.1590/S0100-879X2010007500152

Peters JL, Sutton AJ, Jones DR, Abrams KR, et al. (2006). Comparison of two methods to detect publication bias in metaanalysis. JAMA 295: 676-680. http://dx.doi.org/10.1001/jama.295.6.676

Santos MJ, Fernandes D, Capela S, da Silva JC, et al. (2011). Interleukin-6 promoter polymorphism -174 G/C is associated with nephritis in Portuguese Caucasian systemic lupus erythematosus patients. Clin. Rheumatol. 30: 409-413. http:// dx.doi.org/10.1007/s10067-010-1640-y

Schaid DJ and Jacobsen SJ (1999). Biased tests of association: comparisons of allele frequencies when departing from Hardy-Weinberg proportions. Am. J. Epidemiol. 149: 706-711. http://dx.doi.org/10.1093/oxfordjournals.aje.a009878

Settin A, Hassan H, El-Baz R and Hassan T (2009). Association of cytokine gene polymorphisms with psoriasis in cases from the Nile Delta of Egypt. Acta Dermatovenerol. Alp. Panonica Adriat. 18: 105-112.

Sobti RC, Berhane N, Mahedi SA, Kler R, et al. (2010). Polymorphisms of IL-6 174 G/C, IL-10 -592 C/A and risk of HIV/AIDS among North Indian population. Mol. Cell. Biochem. 337: 145-152. http://dx.doi.org/10.1007/s11010$\underline{009-0293-0}$

Terry CF, Loukaci V and Green FR (2000). Cooperative influence of genetic polymorphisms on interleukin 6 transcriptional regulation. J. Biol. Chem. 275: 18138-18144. http://dx.doi.org/10.1074/jbc.M000379200

Torres T, Bettencourt N, Ferreira J, Carvalho C, et al. (2015). Influence of interleukin-6 gene polymorphisms in epicardial adipose tissue and coronary artery calcification in patients with psoriasis. Br. J. Dermatol. 172: 534-536. http:// dx.doi.org/10.1111/bjd.13271

Totaro F, Cimmino F, Pignataro P, Acierno G, et al. (2013). Impact of interleukin-6 -174 G $>\mathrm{C}$ gene promoter polymorphism on neuroblastoma. PLoS One 8: e76810. http://dx.doi.org/10.1371/journal.pone.0076810 
Vural P, Değirmencioğlu S, Saral NY and Akgül C (2010). Tumor necrosis factor alpha (-308), interleukin-6 (-174) and interleukin-10 (-1082) gene polymorphisms in polycystic ovary syndrome. Eur. J. Obstet. Gynecol. Reprod. Biol. 150: 61-65. http://dx.doi.org/10.1016/j.ejogrb.2010.02.010

Yang Z, Liang Y, Qin B and Zhong R (2014). A meta-analysis of the association of IL-6 -174 G/C and -572 G/C polymorphisms with systemic lupus erythematosus risk. Rheumatol. Int. 34: 199-205. http://dx.doi.org/10.1007/ s00296-013-2855-4

Yin YW, Hu AM, Sun QQ, Liu HL, et al. (2012). Association between interleukin-6 gene -174 G/C polymorphism and the risk of coronary heart disease: a meta-analysis of 20 studies including 9619 cases and 10,919 controls. Gene 503: 25-30. http://dx.doi.org/10.1016/j.gene.2012.04.075

Zhuang L, Ma W, Cai D, Zhong H, et al. (2013). Associations between tumor necrosis factor-a polymorphisms and risk of psoriasis: a meta-analysis. PLoS One 8: e68827. http://dx.doi.org/10.1371/journal.pone.0068827

Zintzaras E and Ioannidis JP (2005). Heterogeneity testing in meta-analysis of genome searches. Genet. Epidemiol. 28 : 123-137. http://dx.doi.org/10.1002/gepi.20048 